\title{
Expression patterns of intronic microRNAs in Caenorhabditis elegans
}

\author{
Meltem Isik, Hendrik C Korswagen, Eugene Berezikov*
}

\begin{abstract}
Background: MicroRNAs (miRNA) are an abundant and ubiquitous class of small RNAs that play prominent roles in gene regulation. A significant fraction of miRNA genes reside in the introns of the host genes in the same orientation and are thought to be co-processed from the host gene mRNAs and thus depend on the host gene promoter for their expression. However, several lines of evidence for independent expression of intronic miRNAs exist in the literature but the extent of this independence remains unclear.

Results: We performed a systematic analysis of genomic regions surrounding intronic miRNAs in the nematode Caenorhabditis elegans and found that, in many cases, there are extended intronic sequences immediately upstream of the miRNAs that are well-conserved between the nematodes. We have generated transcriptional green fluorescent protein reporter fusions in transgenic C. elegans lines and demonstrated that, in all seven investigated cases, the conserved sequences show promoter properties and produce specific expression patterns that are different from the host gene expression patterns. The observed expression patterns are corroborated by the published small RNA sequencing data.

Conclusions: Our analysis reveals that the number of intronic miRNAs that do not rely on their host genes for expression is substantially higher than previously appreciated. At least one-third of the same-strand intronic miRNAs in C. elegans posses their own promoters and, thus, could be transcribed independently from their host genes. These findings provide a new insight into the regulation of miRNA genes and will be useful for the analysis of interactions between miRNAs and their host genes.
\end{abstract}

\section{Background}

MicroRNAs (miRNA) are $\sim 22$ nucleotide (nt) singlestranded RNA molecules that originate from hairpin precursors and regulate gene expression at the post transcriptional level by basepairing with target messenger RNA (mRNA) and blocking its translation or inducing its degradation (reviewed in [1]). In specific cases, miRNAs can also stabilize target mRNAs [2] or even activate their translation [3]. Substantial progress has been made in recent years in the understanding of miRNA biogenesis process (reviewed in [4]). Most miRNA genes are transcribed by RNA polymerase II as long primary transcripts, or primary (pri)-miRNAs [5,6], but some miRNAs can be also transcribed by RNA polymerase III [7]. The pri-miRNA transcripts fold into

\footnotetext{
* Correspondence: e.berezikov@hubrecht.eu

Hubrecht Institute, Royal Netherlands Academy of Arts and Sciences and University Medical Center Utrecht, Uppsalalaan 8, 3584CT Utrecht, The Netherlands
}

stem-loop structures that are recognized and cleaved in the nucleus by RNase III-type nuclease Drosha $[8,9]$ to release precursor miRNA hairpins (pre-miRNAs). Drosha functions together with the Pasha-DGCR8 cofactor, which recognizes the RNA substrate $[10,11]$; the Drosha-containing protein complex is called a Microprocessor. Recently, it has been shown that the Microprocessor is not only involved in miRNA biogenesis but can also directly regulate the stability of mRNAs by processing mRNA-embedded hairpins [12]. The pre-miRNAs hairpins produced by the Microprocessor are exported from the nucleus by exportin 5 [13-15] and further processed by another RNase III-type nuclease Dicer [16-20]. The strand with less stable basepairing at its 5 ' end in the resulting 22 nt RNA duplex is loaded into Argonaute protein within RNA-induced silencing complex (RISC) and becomes mature miRNA, whereas the other strand, miRNA*, is degraded [21,22]. 
MiRNA genes are present in a genome as independent transcriptional units or embedded in introns of other genes (host genes) in a sense or antisense strand orientation [23]. While miRNAs residing in introns of genes in antisense orientation are, by definition, transcribed independently from the host gene, it has been assumed that sense-oriented intronic miRNAs are produced from the common transcript with their host genes - that is, they rely on the host gene promoters for their transcription [1] - and, thus, the expression of such miRNAs can be deduced from the expression patterns of the host genes. Indeed, a good correlation between the expression of miRNAs and their host genes has been observed in human microarray experiments [24]. Studies on the dynamics of pre-miRNA cropping by Drosha revealed that splicing is not required for the production of intronic miRNAs [25] and Drosha cleavage occurs co-transcriptionally without affecting the splicing of the host gene [26,27]. A separate type of intronic miRNAs, called mirtrons, bypasses the Drosha cropping altogether and, instead, relies on the splicing of the host gene to produce pre-miRNA molecules [28-30].

Although substantial experimental data exists to support the 'common transcript' model of biogenesis of intronic miRNAs, there is growing evidence that many sense-strand intronic miRNA are, in fact, transcribed independently from their host genes. Aboobaker et al. found that the in situ hybridization pattern of mir-7 miRNA in Drosophila is different from its host gene bancal: while bancal is expressed ubiquitously, mir-7 has a very specific spatiotemporal expression pattern, suggesting differences in the cis-regulation of this miRNA and the host gene [31]. Similarly, independent transcription of Drosophila mir-281 and its host gene ODA has recently been reported [32]. In humans, histone modification and RNA polymerase II occupation studies using ChiP-seq (chromatin immunoprecipitation) approaches, which can identify regions of transcription initiation or elongation, suggest that almost one-third of intronic miRNA have independent promoters [33-35]. Finally, regions directly upstream of the pre-miRNAs of two C. elegans intronic miRNAs were slow to drive the specific expression of GFP reporters in transgenic animals, demonstrating promoter capabilities of these intronic upstream sequences [36]. It remains unclear, however, whether independent transcriptions of intronic miRNAs and their host genes is an exception or a rule.

Here we perform a systematic study of sense-strand intronic miRNAs in C. elegans and show that all intronic miRNAs that have conserved upstream sequences can be transcribed from their own promoters and have specific and distinct expression patterns that differ from expression patterns of host gene promoters. Our results suggest that independent transcription of intronic
miRNAs is a more frequent phenomenon than previously appreciated. The generated transgenic lines expand the set of $C$. elegans miRNA with known expression patterns and would be useful for further investigation of the biological roles of miRNAs in the worm.

\section{Results and discussion}

\section{Many intronic miRNAs in C. elegans have conserved} upstream sequences

There are currently 155 annotated C. elegans miRNA genes (miRBase v.13), of which 103 reside in intergenic regions, 31 are embedded within an intron of a protein coding gene in a sense orientation and 21 are antisense intronic miRNAs. We first evaluated the promoter potential of upstream sequences of sense-oriented intronic miRNAs using sequence conservation between nematodes as a proxy to its functional load. From the total of 31 intronic miRNAs, 10 are located close to the exon boundary (less than $300 \mathrm{nt}$ ) and, thus, are less likely to posses own promoters, four miRNAs are mirtrons and five other miRNAs are probably not true miRNAs but wrongly annotated miRNA-like hairpins (Additional file 1). Of the remaining 12 miRNAs only three do not show conservation in the upstream sequences (mir-1829b, mir-1829c and mir-1830), while nine miRNAs have extensive conservation patterns spanning up to several hundred bases (Figure 1). The observed conservation patterns exceed an average conservation level of intronic sequences and, thus, could indicate presence of the promoter regions. Indeed, a promoter activity has been previously demonstrated for three of these regions (Table 1) - lin-4 [36-38], mir-2 and mir-82 [36]. The combination of observed conservation patterns and experimental evidence of promoter activity for some of the intronic miRNA upstream regions prompted us to experimentally evaluate promoter activity of the remaining intronic miRNAs with conserved upstream regions.

\section{Conserved upstream sequences of intronic miRNAs have specific promoter activities}

Transcriptional reporters, where promoter of interest is fused with GFP, are widely used to investigate gene expression patterns in C. elegans [39], and this approach was recently successfully applied to study the expression of 89 worm miRNAs. In order to investigate whether the conserved sequences upstream of intronic miRNAs can function as promoters, we similarly fused the selected regions of seven miRNAs to GFP reporters and established a number of transgenic C. elegans lines using a biolistic transformation [40]. In a previous miRNA promoter study Martinez et al. used up to $2 \mathrm{~kb}$ intergenic sequences upstream of pre-miRNA in order to define the promoter regions [36]. Here we restricted 

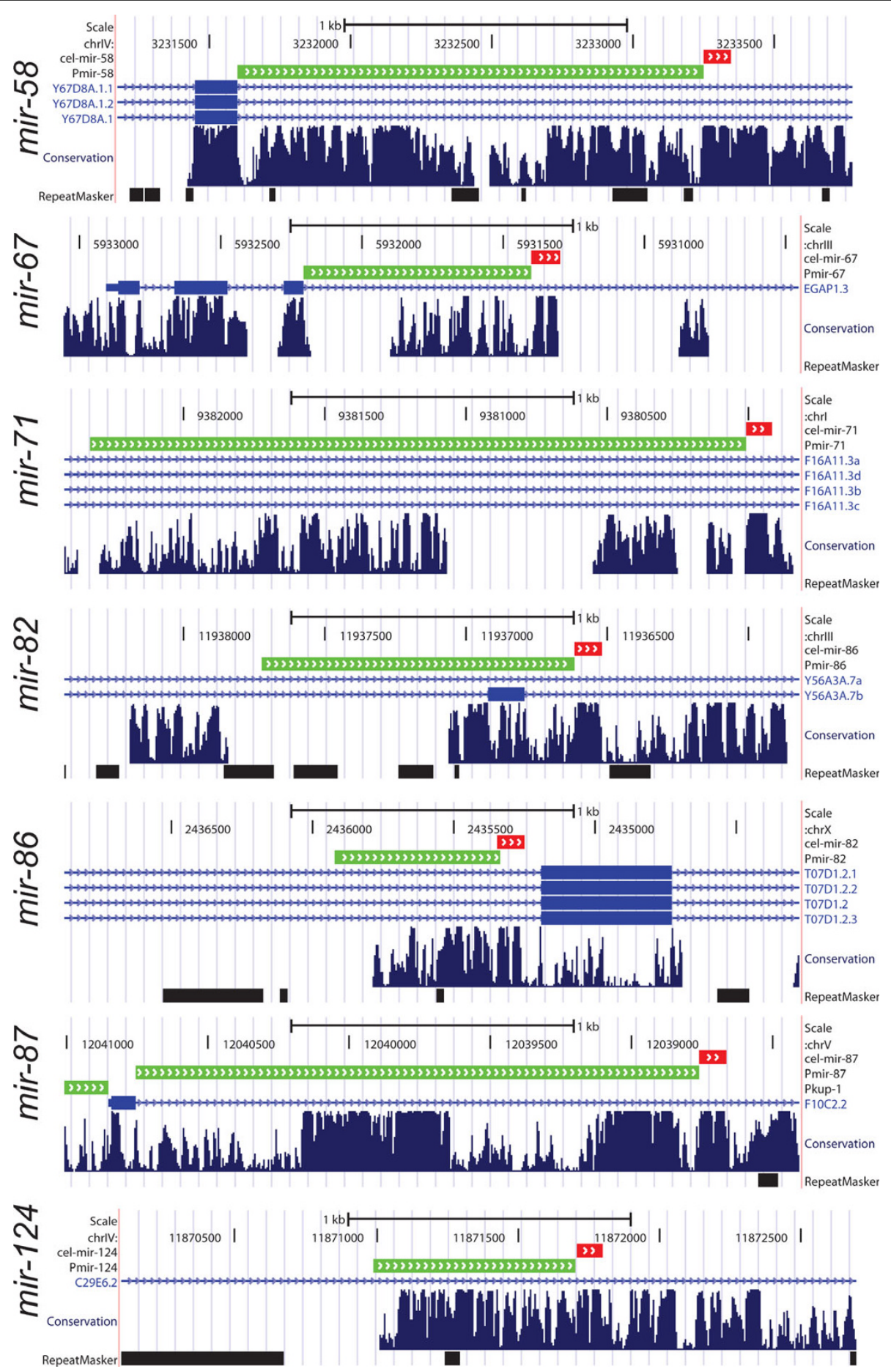

Figure 1 Conservation patterns of upstream regions of intronic microRNAs (miRNA). The miRNA stem-loop regions are shown by red tracks, the regions selected as promoters for transcriptional gfp fusions are shown in green. The images are generated using UCSC genome browser [47]. Conservation tracks are based on comparison of six nematode species genomes: Caenorhabditis elegans, C. briggsae, C. brenneri, C. japonica, C. remanei and Pristionchus pacificus. 
Table 1 Expression patterns of the same-strand intronic microRNAs (miRNAs) and their host genes.

\begin{tabular}{|c|c|c|c|}
\hline miRNA & Pmir::gfp expression pattern & $\begin{array}{l}\text { Host } \\
\text { gene }\end{array}$ & Host gene expression pattern \\
\hline $\operatorname{lin}-4$ & $\begin{array}{l}\text { Expression seen from late } L 1 \text { to adult stages; weak expression } \\
\text { detected ubiquitously (except germline), stronger in pharynx, } \\
\text { vulva, vulval muscle, body wall muscle [36-38]. }\end{array}$ & F59G1.4 & $\begin{array}{l}\text { Expressed in head neurons: inner labial neurons, amphids and } \\
\text { phasmids [50]. }\end{array}$ \\
\hline mir-2 & $\begin{array}{l}\text { Expressed from late embryos to adulthood; strong expression } \\
\text { detected in many neurons including nerve ring, dorsal nerve } \\
\text { cord, ventral nerve cord and also neurons in the tail [36]. }\end{array}$ & ppfr-1 & $\begin{array}{l}\text { Intestine, ventral nerve cord, body wall muscle, vulval muscle, } \\
\text { weak expression in pharynx, some neurons in head and tail } \\
\text { [This study]. }\end{array}$ \\
\hline mir-58 & $\begin{array}{l}\text { Excretory canal, excretory cell soma, pharynx, intestine, } \\
\text { hypodermis, spermatheca, absent in nervous system and in } \\
\text { seam cells; expressed at all stages, adults have the highest } \\
\text { expression [This study]. Note: no expression detected in [36]. }\end{array}$ & Y67D8A.1 & Nervous system [This study]. \\
\hline mir-67 & $\begin{array}{l}\text { Muscle cells (vulval, body wall and intestinal), not pharyngeal } \\
\text { muscles; expressed at all stages, embryos and adults have the } \\
\text { highest expression [This study]. }\end{array}$ & $z m p-1$ & $\begin{array}{l}\text { Expressed in vulA, vulD and vulE but not vulF cells; the } \\
\text { expression in vulD and vulE was present from late } L 4 \text {, whereas } \\
\text { the expression in vulA started later in the adult }[51,52] \text {. }\end{array}$ \\
\hline mir-71 & $\begin{array}{l}\text { Body wall muscle, hypodermis, spermatheca, somatic gonad, } \\
\text { excretory cell, intestine; expressed at all stages of the worm, } \\
\text { very low expression in embryos and L2 animals, highest } \\
\text { expression in L1s and adults [This study]. }\end{array}$ & ppfr-1 & $\begin{array}{l}\text { Intestine, ventral nerve cord, body wall muscle, vulval muscle, } \\
\text { weak expression in pharynx, some neurons in heads and tail } \\
\text { [This study]. }\end{array}$ \\
\hline mir-82 & $\begin{array}{l}\text { Two amphid neurons, excretory gland cell, subset of neurons } \\
\text { in the tail; expressed at all stages, highest expression in } L 4 \mathrm{~s} \\
\text { and adults [This study]. } \\
\text { Expression detected from } L 4 \text { to adults in the pharyngeal } \\
\text { muscle, developing spermatheca, subset of ventral nerve cord } \\
\text { and a subset of amphid neurons [36]. }\end{array}$ & T07D1.2 & Early E lineage [53]. \\
\hline mir-86 & $\begin{array}{l}\text { Ventral nerve cord (some cells), dorsal nerve cord, subset of } \\
\text { neurons in the tail, many neurons in the nerve ring; expressed } \\
\text { at all stages, highest expression in L2s [This study]. }\end{array}$ & Y56A3A.7 & $\begin{array}{l}\text { Intestine, pharynx, excretory system, somatic gonad, } \\
\text { spermatheca, hypodermis [This study]. }\end{array}$ \\
\hline mir-87 & $\begin{array}{l}\text { Ubiquitous expression, strong expression in hypodermis, less } \\
\text { expression in seam cells, anterior and posterior bulb of } \\
\text { pharynx and nerve cord; expressed at all stages, highest } \\
\text { expression in } L 4 \mathrm{~s} \text { and lowest expression in L2 [This study]. }\end{array}$ & kup-1 & $\begin{array}{l}\text { Low and ubiquitous expression, also in embryos and germline } \\
\text { [This study]. }\end{array}$ \\
\hline mir-124 & Nervous system [This study]. & trpa-1 & $\begin{array}{l}\text { Many tissues, including pharyngeal muscle and body wall } \\
\text { muscle, the excretory system, the rectal gland cell, vulval } \\
\text { epithelium, epithelial cells in the head, and the spermatheca, } \\
\text { the majority of amphid sensory neurons and the phasmid } \\
\text { neurons PHA and PHB, sensory neurons OLQ and IL1, other } \\
\text { neurons in the head and ventral nerve cord [54]. }\end{array}$ \\
\hline
\end{tabular}

the promoter regions by either the upstream exon boundary of host genes or by the drop in conservation pattern, usually due to the presence of a repeat element. Regions selected for testing included five miRNAs that were not previously studied (mir-67, mir-71, mir-86, mir-87 and mir-124) and two miRNAs (mir-58 and mir82) for which GFP fusions were published [36] (Figure 1 and Additional file 2).

For all of the seven investigated regions we observed distinct GFP expression patterns (Table 1) supported by at least three independent transgenic lines each. The expression pattern of mir-82 obtained in our study concurs with the previously published expression pattern of this miRNA [36]. In addition, we observed a very strong expression of mir-58 at all developmental stages in excretory cells, epidermis and intestine of C. elegans (Table 1), whereas Martinez et al. did not detect expression of the Promoter::gfp fusion for this miRNA [36]. The small RNA cloning data suggest that miR-58 is the most abundant miRNA expressed at all developmental stages of $C$. elegans and presumably plays a housekeeping role [41], which fits with the Pmir-58::gfp expression patterns observed in our transgenic lines. Interestingly, the mir-58 promoter region tested by Martinez et al. spans $2 \mathrm{~kb}$ upstream of pre-miRNA and includes short upstream exon and part of another intron [36], whereas the sequence used in our study is 350 bases shorter and spans the region between pre-miRNA and the upstream exon. Perhaps the presence of this exon outside of its native genomic context influenced the activity of the downstream promoter region in the previous study.

Promoter regions of several intronic miRNAs show tissue-specific expression: mir-86 and mir-124 are expressed only in neuronal cells and mir-67 is expressed only in muscle cells (Table 1 ). The remaining two miRNAs, mir-71 and mir-87, show broad expression patterns. Interestingly, mir-71 is expressed at all stages and in all cells excluding germline (Table 1), whereas mir-2, which resides in a different intron of the same host gene $p p f r-1$, is prominently expressed in neurons [36]. 
Moreover, small RNA cloning data reveals dynamic changes in expression of miR-71, with significant upregulation at the mid-L1 stage, down-regulation at midL2 stage and recurrent up-regulation after mid-L4 stage [41], and our Pmir-71::gfp transgenic lines recapitulate this small RNA cloning pattern (Figure 2). For mir-67, mir-82, mir-86, mir-87 and mir-124 the relative small RNA cloning frequencies are low (less than $0.2 \%$ of total miRNA reads) but detectable at all developmental stages [41] and corroborate temporal expression patterns observed in our study (Figure 2).

\section{Comparison of expression patterns of host gene promoters and intronic miRNAs}

We next compared the expression patterns driven by host gene promoters and predicted intronic miRNA promoters. For three of the host genes (trpa-1, T07D1.2 and $z m p-1)$ expression patterns were already available in the literature, and for the other four genes (Y67D8A.1, Y56A3A.7, kup-1 and ppfr-1) we have generated transcriptional GFP reporter fusions (Figure 3). For some miRNA/host gene pairs we observed partially overlapping expression patterns, while for some pairs the
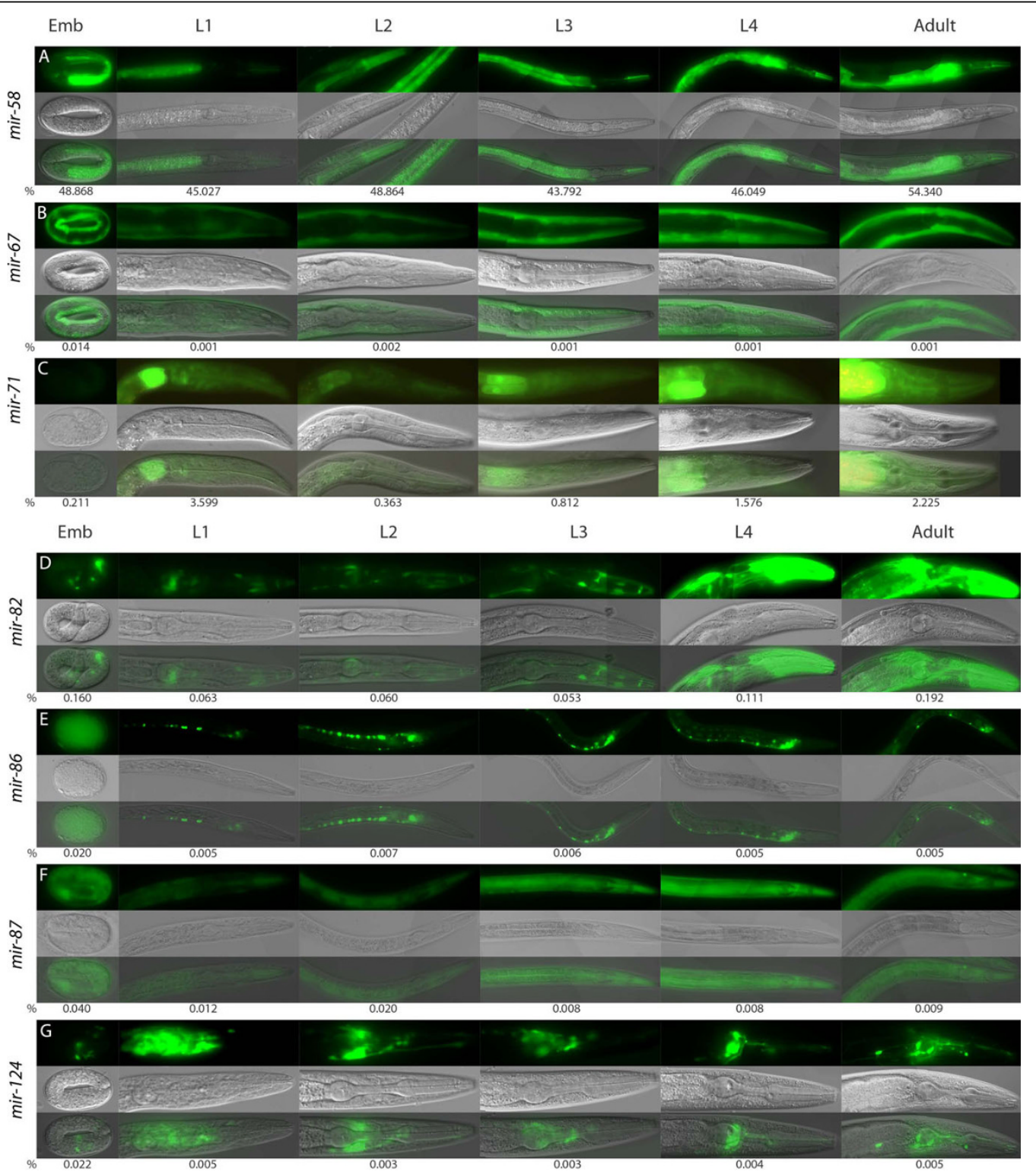

Figure 2 Stage-specific changes in expression of PmiRNA transgenes. The panels consist of green fluorescent protein (top), differential interference contrast (middle) and overlap (bottom) images. The representative regions are shown for different miRNAs. The numbers below the panels are drawn from small RNA cloning data by Kato et al. [41] and represent percentages of the miRNA reads from the total number of miRNA reads in a given developmental stage. (A) Pmir-58; (B) Pmir-67; (C) Pmir-71; (D) Pmir-82; (E) Pmir-86; (F) Pmir-87; (G) Pmir-124. 


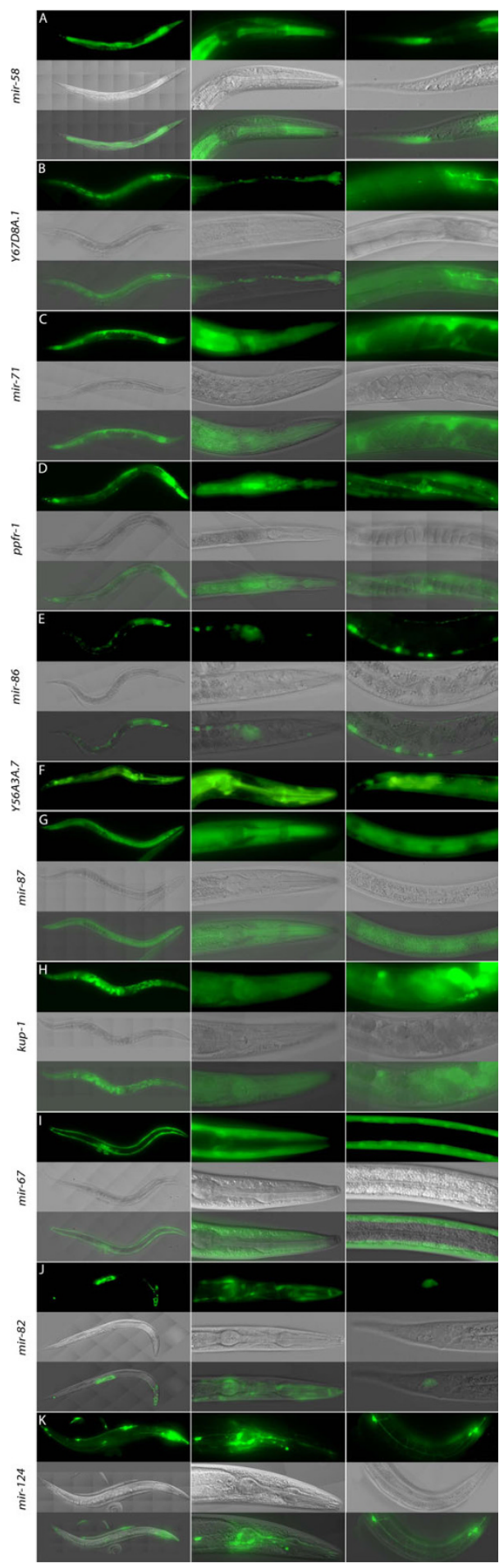

Figure 3 Expression patterns of intronic microRNA promoters and their host gene promoters identified by transcriptional $g f p$ fusions. The panels consist of green fluorescent protein (top), differential interference contrast (middle) and overlap (bottom) images, and three panels in a row are shown per promoter, including whole worm and representative regions. (A) Pmir-58; (B) PY67D8A.1; (C) Pmir-71; (D) Pppfr-1; (E) Pmir-86; (F) PY56A3A; (G) Pmir87; (H) Pkup-1; (I) Pmir-67; (J) Pmir-82; (K) Pmir-124. expression patterns appeared to be completely nonoverlapping (Table 1). The latter include mir-58, which is expressed in multiple tissues but not in the nervous system, while the host gene Y67D8A.1 is expressed only in nervous system. The mir-86/Y56A3A.7 pair shows an opposite pattern: mir-86 is expressed exclusively in the nervous system, while the host gene is expressed in the intestine, pharynx, excretory system and somatic gonad but not in neurons. The pairs with partially overlapping expression patterns include mir-87/kup-1 (ubiquitous expression), mir-67/zmp-1 (non-pharyngeal/vulval muscles) and mir-71/ppfr-1 (body wall muscle).

\section{Host gene-dependent or independent expression of intronic miRNAs?}

It is recognized that the promoter fusions only approximate the expression patterns of the genes and that the actual expression can be different due to a number of factors, including incompleteness of cis-regulatory elements used in the reporters, genomic context, copy number and posttranscriptional regulation [39], in the majority of the investigated cases GFP reporters recapitulate gene expression quite faithfully [42]. In the case of miRNA genes, the expression patterns established by GFP reporters should ultimately be confirmed by in situ hybridization experiments. Unfortunately, miRNA in situ in C. elegans this proved to be extremely difficult and, to our knowledge, no successful procedure has so far been developed. Thus, we have used indirect evidence to investigate the expression patterns of intronic miRNA genes.

The first discovered miRNA gene, lin-4, was initially classified as an intergenic miRNA and shown to have a functional upstream promoter [36-38]. It was realized only recently that, in fact, this miRNA resides in a large intron of a protein-coding gene [36]. In addition, two other intronic miRNAs (mir-2 and mir-82) were recently shown to have their own promoters [36].

Here we show that many intronic miRNA genes have conserved intronic upstream sequences, which can drive specific expression of transcriptional GFP fusions in transgenic C. elegans animals. The observed expression patterns are only partially overlapping, or completely non-overlapping, with the expression patterns of host genes. However, the presence of functional promoters in intronic sequences does not exclude the parallel production of mature miRNAs from the host gene transcripts by the mechanisms elucidated previously (reviewed in [4]). At the same time, small RNA cloning data from various developmental stages of $C$. elegans [41] support expression patterns derived from the intronic promoters rather than from the host genes for several investigated miRNAs (mir-71, mir-58). 
Many miRNA genes in C. elegans exist as families that share the same seed sequence (reviewed in [1]). Such miRNAs are thought to evolve by duplication of the ancestral miRNA loci followed by divergent evolution [43-46]. Interestingly, in the mir-80 family of miRNAs there is one intergenic (mir-80), one antisense intronic (mir-81) and one sense intronic (mir-82) miRNA; the sense and antisense intronic miRNAs reside in the same host gene but in the different introns. Since intergenic mir-80 and intronic antisense mir-81 should have their own promoters, and we and Martinez et al. [36] show that intronic sense-oriented mir-82 also has an intronic promoter, the most parsimonious explanation of the evolution of the mir-80 family is by the duplication of the locus, which included the promoter region of the ancestral miRNA. In this case, the expression patterns of mir-80 family members are expected to be similar and, indeed, both mir-80 and mir-82 have overlapping expression in excretory cells, head neurons and head muscles (Table 1 and [36]).

Evidence of the independent expression of intronic miRNAs and their host genes also exists in other species. In Drosophila, Aboobaker et al. demonstrated, by in situ hybridization experiments, different expression patterns for mir-7 and the host gene bancal [31], while Xiong et al. showed the independence of mir-281 and the host gene ODA [32]. In humans, almost one-third of intronic miRNAs are estimated to have independent promoter regions based on RNA polymerase II occupation and chromatin modification studies [33-35], although no direct promoter activity has yet been demonstrated. Thus, there is substantial combined evidence to support the independent transcription of some intronic miRNAs. At the same time, more than half of the same-strand intronic miRNAs in C. elegans are located in introns close to the exon boundaries (Additional file 1) and, thus, are less likely to have independent promoters but, rather, rely on host genes for their expression. We propose that such 'true' intronic miRNAs could evolve in two ways. In one scenario, an independently transcribed miRNA first becomes embedded in an intron of a host gene, in a sense or antisense orientation, and such integration in an actively transcribed genomic region could provide evolutionary advantages. In support of this 'open chromatin embedding' hypothesis, there is a comparable number of sense and antisense intronic miRNAs in C. elegans (31 versus 21 , respectively). Later, the transcription of some senseoriented intronic miRNAs is gradually switched from the intronic promoter to transcription from their host genes, the intronic promoter loses its function and the miRNAs becomes 'true' intronic miRNA. In the alternative scenario, some host gene-reliant miRNAs evolved in the intronic sequences de novo and were never transcribed from their own promoters; mirtrons are the ultimate example of such an evolutionary scenario [28]. Thus, two types of intronic miRNAs could be distinguished: true intronic miRNAs are processed as part of host gene transcripts and independent intronic miRNAs that reside in introns of genes in the sense orientation but can be transcribed from their own intronic promoters. These independent intronic miRNAs could also be processed from the host gene transcripts and, thus, the cumulative expression pattern of such miRNAs is probably composed of expression driven by the host gene promoter and the intronic miRNA promoter. Interestingly, processing of the mRNA-embedded hairpins by the Microprocessor complex has been recently recognized as an independent gene regulatory pathway [12], and investigation of the interplays between specific intronic miRNAs and their host genes would be a promising future direction in miRNA research.

\section{Conclusions}

We have analysed the genomic environment of intronic miRNAs and found that almost half of the same-strand intronic miRNAs have long regions of extensive conservation immediately upstream of the pre-miRNAs. All of the seven tested conserved regions drive GFP expression in transgenic $C$. elegans and produce expression patterns that are different from the expression patterns of the host genes but are supported by the small RNA cloning data. Our results, combined with the previously published data for two additional intronic miRNAs, provide evidence for the presence of independent promoter regions for nine intronic miRNA genes and suggest that the fraction of intronic miRNAs that are transcribed independently from the host genes is higher than previously appreciated. The generated expression profiles of intronic miRNA promoters will be valuable for further studies of interactions between intronic miRNAs and their host genes.

\section{Materials and methods Construction of Pmir::gfp reporters}

We used the UCSC genome browser [47] to determine the conserved regions upstream of the predicted stemloop sequence of intronic miRNAs. These conserved regions were cloned as the promoter regions upstream of the $g f p$ gene with let-858 3' untranslated region. The following Pmir::gfp constructs were generated by the restriction enzyme-based cloning (NotI and AflII sites) into the pCFJ151-p5605 vector [48] that also contains unc-119 selection gene: Pmir-58, Pmir-67, Pmir-71, Pmir-82, Pmir-86, Pmir-87 and Pmir-124, PY67D8A.1, Pppfr-1, PY56A3A.7 and Pkup-1. The primers that were used for the amplification of the promoter sequences 
from the N2 genomic DNA are provided in Additional file 2 .

\section{Generation and analysis of transgenic C. elegans lines} Transgenic PmicroRNA::gfp animals were generated by biolistic transformation of the DP38 (unc-119(ed3)) C. elegans strain as described previously [40], except Ppprf-1::gfp lines, which were generated by microinjection with rol-6 transformation marker [49]. One or several bombardments were performed for every construct until at least three independent transgenic lines were obtained. For every transgenic line, mixed populations of hermaphrodites were examined by fluorescence microscopy. We recorded the expression pattern conferred by each miRNA promoter that was consistent in each of the independently derived transgenic lines.

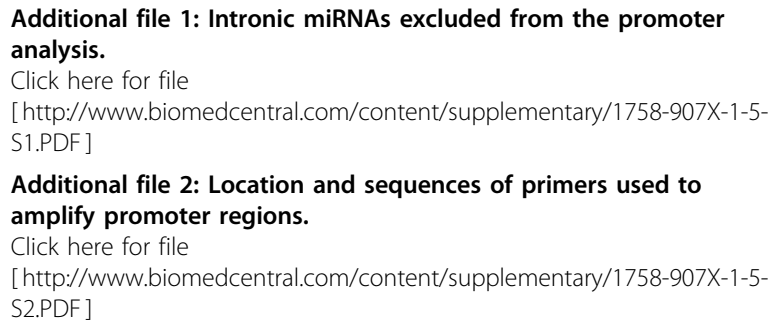

\section{Abbreviations}

GFP: green fluorescent protein; mRNA: messenger RNA; miRNA: microRNA; nt: nucleotide; pre: precursor; priRNA: primary RNA.

\section{Acknowledgements}

We thank René Ketting for the critical comments on the manuscript. The pCFJ151-p5605 vector was a gift from Eric Jorgensen. The DP38 strain used in this work was provided by the Caenorhabditis Genetics Center, which is funded by the NIH National Center for Research Resources (NCRR). This work is supported by a VIDI grant from The Netherlands Organization for Scientific Research (NWO) to EB.

\section{Authors' contributions}

EB designed the experiment. Ml generated constructs and transgenic lines. MI, HCK and EB analysed the data and wrote the manuscript.

\section{Competing interests}

The authors declare that they have no competing interests.

Received: 9 July 2009

Accepted: 1 February 2010 Published: 1 February 2010

\section{References}

1. Bartel DP: MicroRNAs: genomics, biogenesis, mechanism, and function. Cell 2004, 116:281-297.

2. Schratt GM, Tuebing F, Nigh EA, Kane CG, Sabatini ME, Kiebler M, Greenberg ME: A brain-specific microRNA regulates dendritic spine development. Nature 2006, 439:283-289.

3. Vasudevan S, Tong Y, Steitz JA: Switching from repression to activation: microRNAs can up-regulate translation. Science 2007, 318:1931-1934.

4. Kim VN, Han J, Siomi MC: Biogenesis of small RNAs in animals. Nat Rev Mol Cell Biol 2009, 10:126-139.
5. Cai $X$, Hagedorn $\mathrm{CH}$, Cullen BR: Human microRNAs are processed from capped, polyadenylated transcripts that can also function as mRNAs. RNA 2004, 10:1957-1966.

6. Lee Y, Kim M, Han J, Yeom KH, Lee S, Baek SH, Kim VN: MicroRNA genes are transcribed by RNA polymerase II. EMBO J 2004, 23:4051-4060.

7. Borchert GM, Lanier W, Davidson BL: RNA polymerase III transcribes human microRNAs. Nat Struct Mol Biol 2006, 13:1097-1101.

8. Lee $Y$, Jeon K, Lee JT, Kim S, Kim VN: MicroRNA maturation: stepwise processing and subcellular localization. EMBO J 2002, 21:4663-4670.

9. Lee Y, Ahn C, Han J, Choi H, Kim J, Yim J, Lee J, Provost P, Radmark O, Kim S, Kim VN: The nuclear RNase III Drosha initiates microRNA processing. Nature 2003, 425:415-419.

10. Denli AM, Tops BB, Plasterk RH, Ketting RF, Hannon GJ: Processing of primary microRNAs by the Microprocessor complex. Nature 2004, 432:231-235.

11. Gregory RI, Yan KP, Amuthan G, Chendrimada T, Doratotaj B, Cooch N Shiekhattar R: The Microprocessor complex mediates the genesis of microRNAs. Nature 2004, 432:235-240.

12. Han J, Pedersen JS, Kwon SC, Belair CD, Kim YK, Yeom KH, Yang WY, Haussler D, Blelloch R, Kim VN: Posttranscriptional crossregulation between Drosha and DGCR8. Cell 2009, 136:75-84.

13. Yi R, Qin Y, Macara IG, Cullen BR: Exportin-5 mediates the nuclear export of pre-microRNAs and short hairpin RNAs. Genes Dev 2003, 17:3011-3016

14. Bohnsack MT, Czaplinski K, Gorlich D: Exportin 5 is a RanGTP-dependent dsRNA-binding protein that mediates nuclear export of pre-miRNAs. RNA 2004, 10:185-191.

15. Lund E, Guttinger S, Calado A, Dahlberg JE, Kutay U: Nuclear export of microRNA precursors. Science 2004, 303:95-98.

16. Grishok A, Pasquinelli AE, Conte D, Li N, Parrish S, Ha I, Baillie DL, Fire A, Ruvkun G, Mello CC: Genes and mechanisms related to RNA interference regulate expression of the small temporal RNAs that control C. elegans developmental timing. Cell 2001, 106:23-34.

17. Hutvagner G, McLachlan J, Pasquinelli AE, Balint E, Tuschl T, Zamore PD: A cellular function for the RNA-interference enzyme Dicer in the maturation of the let-7 small temporal RNA. Science 2001, 293:834-838.

18. Ketting RF, Fischer SE, Bernstein E, Sijen T, Hannon GJ, Plasterk RH: Dicer functions in RNA interference and in synthesis of small RNA involved in developmental timing in C. elegans. Genes Dev 2001, 15:2654-2659.

19. Knight SW, Bass BL: A role for the RNase III enzyme DCR-1 in RNA interference and germ line development in Caenorhabditis elegans. Science 2001, 293:2269-2271.

20. Abbott AL, Alvarez-Saavedra E, Miska EA, Lau NC, Bartel DP, Horvitz HR, Ambros $V$ : The let-7 MicroRNA family members mir-48, mir-84, and mir241 function together to regulate developmental timing in Caenorhabditis elegans. Dev Cell 2005, 9:403-414.

21. Khvorova A, Reynolds A, Jayasena SD: Functional siRNAs and miRNAs exhibit strand bias. Cell 2003, 115:209-216.

22. Schwarz DS, Hutvagner G, Du T, Xu Z, Aronin N, Zamore PD: Asymmetry in the assembly of the RNAi enzyme complex. Cell 2003, 115:199-208.

23. Rodriguez A, Griffiths-Jones S, Ashurst JL, Bradley A: Identification of mammalian microRNA host genes and transcription units. Genome Res 2004, 14:1902-1910.

24. Baskerville $S$, Bartel DP: Microarray profiling of microRNAs reveals frequent coexpression with neighboring miRNAs and host genes. RNA 2005, 11:241-247.

25. Kim YK, Kim VN: Processing of intronic microRNAs. EMBO J 2007, 26:775-783.

26. Morlando M, Ballarino M, Gromak N, Pagano F, Bozzoni I, Proudfoot NJ: Primary microRNA transcripts are processed co-transcriptionally. Nat Struct Mol Biol 2008, 15:902-909.

27. Kataoka N, Fujita M, Ohno M: Functional association of the Microprocessor complex with the spliceosome. Mol Cell Biol 2009, 29:3243-3254.

28. Berezikov E, Chung WJ, Willis J, Cuppen E, Lai EC: Mammalian mirtron genes. Mol Cell 2007, 28:328-336.

29. Okamura K, Hagen JW, Duan H, Tyler DM, Lai EC: The mirtron pathway generates microRNA-class regulatory RNAs in Drosophila. Cell 2007, 130:89-100.

30. Ruby JG, Jan $\mathrm{CH}$, Bartel DP: Intronic microRNA precursors that bypass Drosha processing. Nature 2007, 448:83-86. 
31. Aboobaker AA, Tomancak P, Patel N, Rubin GM, Lai EC: Drosophila microRNAs exhibit diverse spatial expression patterns during embryonic development. Proc Natl Acad Sci USA 2005, 102:18017-18022.

32. Xiong H, Qian J, He T, Li F: Independent transcription of miR-281 in the intron of ODA in Drosophila melanogaster. Biochem Biophys Res Commun 2009, 378:883-889

33. Ozsolak F, Poling LL, Wang Z, Liu H, Liu XS, Roeder RG, Zhang X, Song JS, Fisher DE: Chromatin structure analyses identify miRNA promoters. Genes Dev 2008, 22:3172-3183.

34. Corcoran DL, Pandit KV, Gordon B, Bhattacharjee A, Kaminski N, Benos PV: Features of mammalian microRNA promoters emerge from polymerase II chromatin immunoprecipitation data. PLoS One 2009, 4:e5279.

35. Wang $X$, Xuan Z, Zhao X, Li Y, Zhang MQ: High-resolution human corepromoter prediction with CoreBoost_HM. Genome Res 2009, 19:266-275.

36. Martinez NJ, Ow MC, Reece-Hoyes JS, Barrasa MI, Ambros VR, Walhout AJ: Genome-scale spatiotemporal analysis of Caenorhabditis elegans microRNA promoter activity. Genome Res 2008, 18:2005-2015.

37. Esquela-Kerscher A, Johnson SM, Bai L, Saito K, Partridge J, Reinert KL, Slack FJ: Post-embryonic expression of $C$. elegans microRNAs belonging to the lin-4 and let-7 families in the hypodermis and the reproductive system. Dev Dyn 2005, 234:868-877.

38. Ow MC, Martinez NJ, Olsen PH, Silverman HS, Barrasa MI, Conradt B, Walhout AJ, Ambros V: The FLYWCH transcription factors FLH-1, FLH-2, and $\mathrm{FLH}-3$ repress embryonic expression of microRNA genes in $\mathrm{C}$. elegans. Genes Dev 2008, 22:2520-2534.

39. Boulin T, Etchberger JF, Hobert O: Reporter gene fusions. WormBook 2006, $1-23$.

40. Berezikov E, Bargmann $\mathrm{Cl}$, Plasterk RH: Homologous gene targeting in Caenorhabditis elegans by biolistic transformation. Nucleic Acids Res 2004, 32(4):e40.

41. Kato $M$, de Lencastre A, Pincus Z, Slack FJ: Dynamic expression of small non-coding RNAs, including novel microRNAs and piRNAs/21U-RNAs, during Caenorhabditis elegans development. Genome Biol 2009, 10(5):R54.

42. Reece-Hoyes JS, Shingles J, Dupuy D, Grove CA, Walhout AJ, Vidal M, Hope IA: Insight into transcription factor gene duplication from Caenorhabditis elegans Promoterome-driven expression patterns. BMC Genomics 2007, 8:27.

43. Tanzer A, Stadler PF: Molecular evolution of a microRNA cluster. J Mol Biol 2004, 339:327-335

44. Tanzer A, Amemiya CT, Kim CB, Stadler PF: Evolution of microRNAs located within Hox gene clusters. J Exp Zoolog B Mol Dev Evol 2005, 304:75-85.

45. Chen K, Rajewsky N: The evolution of gene regulation by transcription factors and microRNAs. Nat Rev Genet 2007, 8:93-103.

46. Liu N, Okamura K, Tyler DM, Phillips MD, Chung WJ, Lai EC: The evolution and functional diversification of animal microRNA genes. Cell Res 2008, 18:985-996.

47. Kuhn RM, Karolchik D, Zweig AS, Wang T, Smith KE, Rosenbloom KR, Rhead B, Raney BJ, Pohl A, Pheasant M, Meyer L, Hsu F, Hinrichs AS, Harte RA, Giardine B, Fujita P, Diekhans M, Dreszer T, Clawson H, Barber GP, Haussler D, Kent WJ: The UCSC Genome Browser Database: update 2009. Nucleic Acids Res 2009, 37:D755-61.

48. Frokjaer-Jensen C, Davis MW, Hopkins CE, Newman BJ, Thummel JM, Olesen SP, Grunnet M, Jorgensen EM: Single-copy insertion of transgenes in Caenorhabditis elegans. Nat Genet 2008, 40:1375-1383.

49. Mello CC, Kramer JM, Stinchcomb D, Ambros V: Efficient gene transfer in C. elegans: extrachromosomal maintenance and integration of transforming sequences. EMBO J 1991, 10:3959-3970.

50. Vazquez-Manrique RP, Gonzalez-Cabo P, Ortiz-Martin I, Ros S, Baylis HA, Palau F: The frataxin-encoding operon of Caenorhabditis elegans shows complex structure and regulation. Genomics 2007, 89:392-401.

51. Wang M, Sternberg PW: Patterning of the C. elegans 1 degrees vulval lineage by RAS and Wnt pathways. Development 2000, 127:5047-5058.

52. Inoue T, Sherwood DR, Aspock G, Butler JA, Gupta BP, Kirouac M, Wang M, Lee PY, Kramer JM, Hope I, Bürglin TR, Sternberg PW: Gene expression markers for Caenorhabditis elegans vulval cells. Mech Dev 2002, 119(Suppl 1):S203-9.

53. Broitman-Maduro G, Maduro MF, Rothman JH: The noncanonical binding site of the MED-1 GATA factor defines differentially regulated target genes in the C. elegans mesendoderm. Dev Cell 2005, 8:427-433.
54. Kindt KS, Viswanath V, Macpherson L, Quast K, Hu H, Patapoutian A, Schafer WR: Caenorhabditis elegans TRPA-1 functions in mechanosensation. Nat Neurosci 2007, 10:568-577.

doi:10.1186/1758-907X-1-5

Cite this article as: Isik et al:: Expression patterns of intronic microRNAs in Caenorhabditis elegans. Silence 2010 1:5.

\section{Submit your next manuscript to BioMed Central and take full advantage of:}

- Convenient online submission

- Thorough peer review

- No space constraints or color figure charges

- Immediate publication on acceptance

- Inclusion in PubMed, CAS, Scopus and Google Scholar

- Research which is freely available for redistribution

Submit your manuscript at www.biomedcentral.com/submit
C Biomed Central 